\title{
Atenção básica na agenda da saúde
}

\author{
Primary care in the agenda of public \\ health sector in Brazil
}

Regina Bodstein 1

\footnotetext{
1 Departamento de Ciências Sociais, Escola Nacional de Saúde Pública, Fundação Oswaldo Cruz.

Rua Leopoldo Bulhões 1480, 9o andar, Manguinhos, 21041-210 Rio de Janeiro RJ. bodstein@ensp.fiocruz.br
}

\begin{abstract}
The article discusses the policies of reorganization of the primary health care taking the recent process of decentralization of SUS in Brazil. The central government's paper as inducement is emphasized. This can be verified by several measures and specific programs (PAB and PACS/PSF, mainly) that transfer for the municipal level the responsibility with the primary care. So it is in the municipal level that happens the process of implementation of that policies generating effects of difficult evaluation given the diversity of local contexts. The central argument emphasizes the importance of the evaluation process and intermediary results turned to the institutional performance that can be translated in accountability and public commitment, administration capacity and larger control and social participationrather than final effects or more direct impacts on the offer of services. The conclusion is that in spite of all the difficulties and obstacles the process has strengthening the capacity of municipal administration regarding the organization of the primary health care.
\end{abstract}

Key words Primary health care, Decentralization of primary health care, Evaluation in primary health care
Resumo O artigo discute a politica de reorganização da atenção básica a partir do processo recente de descentralização do SUS no Brasil. Enfatiza-se o papel indutor do governo central, que, através de um conjunto de medidas e programas específicos (PAB e PACS/PSF, principalmente), transfere para os municípios a responsabilidade com a atenção básica. Assim, é no nível municipal que ocorre o processo de implementação dessa política, gerando efeitos de difícil avaliação, dada a diversidade de contextos locais. A argumentação central enfatiza a importância de se avaliarem processos e resultados intermediários voltados para o desempenho institucional, que podem ser traduzidos em vontade política e compromisso público, capacidade de gestão e maior controle e participação social, mais do que exatamente efeitos ou impactos mais diretos sobre a oferta de serviços. A conclusão é de que apesar de todas as dificuldades e obstáculos o processo tem implicado o fortalecimento da capacidade de gestão municipal no que diz respeito à organização da atenção básica em saúde. Palavras-chave Atenção básica, Descentralização da atenção básica, Avaliação da atenção básica 


\section{Introdução}

... Para que o geral possa ser apreendido e para que se descubram novas unidades, parece necessário apreendê-lo não diretamente, de uma só vez, mas através de exemplos, diferenças, variações, particularidades - aos pouquinhos, caso a caso. Num mundo estilhaçado, devemos examinar os estilhaços. (Geertz, 2001)

A década de 1990 é marcada pelo avanço do processo de descentralização do setor saúde no Brasil. A esfera municipal, em particular, ainda que de modo lento, gradual e negociado, torna-se a principal responsável pela gestão da rede de serviços de saúde no país e, portanto, pela prestação direta da maioria das ações e programas de saúde. A responsabilização crescente dos municípios com a oferta e com a gestão dos serviços de saúde no começo da nova década é uma realidade inquestionável.

De fato, a esmagadora maioria dos municípios brasileiros assume, a partir de 1998, a implementação da agenda setorial. Tais municípios compõem um cenário fragmentado e de grande diversidade, considerando as imensas desigualdades sociais, regionais e intra-regionais, traço indiscutível da realidade brasileira. Assim, a compreensão e a avaliação das mudanças em curso, do ponto de vista que se defende neste artigo, passa pela perspectiva apontada por Geertz (2001): a compreensão mais geral do processo deve ser buscada a partir da análise da diversidade de situações e de contextos locais. O que está em jogo, portanto, é a avaliação do processo de implementação da descentralização/municipalização em saúde, tomando o devido cuidado com generalizações e conclusões apressadas.

A complexidade da tarefa decorre da necessidade de se tomar como ponto de partida as principais características das mudanças desencadeadas com a implantação do SUS no decorrer da década de 1990. A própria dinâmica descentralizadora, que envolve novos atores e contextos locais diversos, é responsável por um considerável deslocamento e pulverização do processo decisório e, portanto, pela diversidade de cenários locais. Mas a maior dificuldade é dada, sobretudo, pela compreensão de como tais mudanças geram impactos diversos, quer na reorganização das secretarias municipais, quer na estrutura e na composição da rede ou dos sistemas locais, na extensão e na qualidade da assistência e, enfim, nas condições de acesso aos serviços de saúde.
Após uma década de descentralização do setor e da diversidade de experiências de gestão local e apesar do intenso debate sobre o tema, a realidade é que ainda são poucos os estudos e pesquisas de caráter avaliativo, tratando de qualificar as inúmeras mudanças em curso. Assim, a proposta deste artigo é discutir aspectos referentes à implementação do processo de descentralização, tendo como eixo a proposta de reorganização da atenção básica em saúde. Buscase qualificar o contexto de mudanças e inovações deflagrado a partir de um conjunto de medidas, de programas e de normas, voltadas para a chamada atenção básica e para o atendimento primário em saúde. Isto é, programas e políticas especificamente preocupadas com o primeiro nível de acesso e de contato da população com o sistema de saúde. São medidas deliberadas de indução a uma maior organização ou reorganização da porta de entrada aos serviços de saúde, cujo pressuposto, ao que parece, envolve uma alteração no modelo de assistência: predomínio das ações preventivas e de promoção da saúde em detrimento das ações curativas de média e alta complexidade e hospitalares. Dessa forma, parece útil, para o avanço da reflexão no campo da saúde coletiva e para o rumo do debate em torno da descentralização da política de saúde, analisar e sistematizar algumas das principais questões em torno da atenção básica no contexto municipal. Mais do que trazer novos dados ou informações, procura-se aqui uma reflexão sobre os termos do debate da política voltada para a atenção básica no Brasil.

\section{Desafios metodológicos}

O ponto de partida diante do conjunto enorme de mudanças recentes no setor saúde vem da necessidade de se delimitar o que de fato é importante de ser avaliado, tendo em vista os princípios e valores do SUS. Contextos estaduais e municipais favorecem ou não o sucesso da descentralização, revelando a importância das análises qualitativas, dos estudos de caso e das abordagens comparativas. Parece extremamente útil a perspectiva avaliativa no campo das políticas públicas como ferramenta do planejamento e da gestão, podendo revelar o rumo das principais inovações no processo de implementação da política de descentralização do setor saúde.

A avaliação de políticas públicas, preocupada com processos de mudança, com resultados 
e impactos da implementação dos programas e políticas, adquire um papel imprescindível em um contexto democrático, de crescente responsabilização do gestor público e de controle social. As abordagens avaliativas, partindo, freqüentemente, da análise do processo através do qual decisões são transformadas em ações programáticas e projetos de intervenção específicos, trazem enorme riqueza explicativa, mas também desafios metodológicos importantes. A perspectiva avaliativa, centrada na explicação das mudanças concretas decorrentes da gestão pública, procura vincular tais mudanças ao processo decisório e ao planejamento das atividades, mas, por outro lado, trata de separar, para efeitos metodológicos, o processo de formulação e de implementação de políticas, assim como enfatiza a distinção entre planejamento e execução de programas.

Assim, programas e projetos de intervenção, que, na prática, traduzem uma orientação e uma decisão política previamente tomadas, não garantem sua execução e ou implantação, trazendo a indagação sobre em que medida uma determinada intervenção foi ou não de fato implantada. Ora, perguntar sobre o grau de implantação de um determinado programa pressupõe a compreensão do contexto que molda e condiciona sua operacionalização. A conclusão aparentemente banal é de que contextos diversos e processos específicos de implantação influem nos resultados de uma intervenção.

A partir do questionamento sobre a implantação ou não do programa é importante comparar o desenho e as características da intervenção planejada com aquelas da intervenção realmente implantada (Denis \& Champagne, 2000), já que o processo de implementação necessariamente altera e modifica a proposta original. Além disso, soluções e intervenções podem se mostrar eficazes em uma determinada situação e não em outra, o que impõe adequações diversas ao novo contexto.

O monitoramento do processo de implantação é extremamente pertinente visto que a presença de atores, interesses diversos e o cenário político-institucional podem explicar o sucesso ou o fracasso na implantação da proposta, como também a distância entre o planejado e o executado. Portanto, tendo em vista que processos determinam resultados, identificar o contexto de implantação dos programas e intervenções por um lado, e enfatizar a importância da avaliação processual, por outro, são questões cada vez mais enfatizadas na literatura sobre o te- ma (McKinlay, 1996; Hartz, 1999). A análise do contexto de implantação é imprescindível para se alcançar uma compreensão mais global da intervenção (Denis \& Champagne, 2000), identificando processos e resultados intermediários, porém, fundamentais. Processos e resultados intermediários são indispensáveis, por sua vez, não só para uma posterior validade do impacto final (Mohr, 1992), como também freqüentemente sinalizam e evidenciam mudanças mais substanciais em curso.

Como lembra Robert Putnam (1996), é de extrema importância, quando se trata de caracterizar o desempenho institucional, trabalhar com indicadores de adesão e compromisso do poder público, por um lado, e co-responsabilização da população, por outro, antes de se avaliarem resultados e impactos finais. Isto é, na perspectiva avaliativa de políticas e programas sociais, a definição de indicadores e resultados intermediários é extremamente pertinente, já que pode explicar o sentido das mudanças em curso, bem como as diferenças nos impactos finais. O desempenho institucional, na perspectiva de Putnam, ou seja, a capacidade do governo de implementar políticas, solucionar problemas e criar serviços, respondendo às demandas da sociedade, constitui, nesta perspectiva, uma variável-chave.

Em resumo, o que se quer ressaltar aqui é que mudanças no desempenho e, portanto, na gestão de programas e projetos de saúde, promovendo uma nova institucionalidade e maior responsabilidade pública $v i s-\grave{a}$-vis maior participação e controle social são de fato indispensáveis para que ocorram impactos positivos na oferta de serviços e nas condições de vida e saúde da população. Isto é, mudanças na cultura e no compromisso com a gestão pública são indicadores importantes - mesmo quando seus efeitos e resultados finais só venham a ocorrer no médio e longo prazos.

No caso do processo recente da descentralização e da municipalização da saúde, a ênfase deve ser dada nas variáveis explicativas que identifiquem inovações no contexto da gestão, no compromisso e responsabilidade pública ( $a c$ countability). Estas variáveis quase sempre representam processos aparentemente simples, mas que configuram precondições indispensáveis para mudanças e impactos mais substanciais, como por exemplo, no acesso e na qualidade da oferta de serviços médico-sanitários. Como diz Putnam, devemos avaliar resultados diretamente atribuídos ao desempenho dos ser- 
viços de saúde e não as taxas de mortalidade em si, isto é, analisar inovações que nem sempre aparecem refletidas nos clássicos indicadores de saúde da população (Putnam, 1996).

A análise do contexto de implantação e os ajustes entre os princípios do SUS e sua execução como política pública são imprescindíveis quando o que está em jogo é a compreensão e a avaliação das mudanças em curso e os resultados e impactos na saúde da população. Trata-se de perceber que vicissitudes e obstáculos são inevitáveis entre o processo de decisão política e a implementação. Isto é, entre os princípios do SUS, por exemplo, e sua execução no contexto dos estados e municípios brasileiros. De qualquer forma, a avaliação da descentralização/municipalização em curso não pode ignorar os valores e princípios do nosso sistema de saúde e se estão sendo ou foram alcançados. A avaliação pressupõe cotejar a proposta que inspirou o movimento de reforma sanitária no país e as mudanças atualmente em curso. Uma das variáveis-chave, já apontada pela literatura, vem da capacidade técnica-administrativa e do desempenho dos gestores estaduais e municipais do setor saúde.

Importa considerar, por um lado, o conjunto de mudanças no setor saúde vis-à-vis à universalidade do direito à saúde e aos serviços; a integralidade da atenção, pressupondo a oferta pública de ações preventivas e curativas, básicas e de média e alta complexidade; a hierarquização do atendimento, garantindo referência e contra-referência diante dos diversos níveis de complexidade do sistema de saúde e, participação e controle da sociedade civil na gestão do processo, incentivando a formação dos chamados Conselhos de Saúde. São princípios e valores que serviram de inspiração para a reforma do sistema de saúde entre nós e que, de fato, justificam estudos avaliativos mais abrangentes.

Por outro lado, após uma década de mudanças profundas na estrutura normativa do setor, importa identificar indicadores de inovação gerencial e de desempenho institucional das secretarias municipais de saúde. Uma das questões que se defende aqui é a importância da definição de resultados intermediários vinculados ao desempenho setorial mais sensivel e eficaz: sensivel às demandas do eleitorado e eficaz na utilização de recursos limitados para atender a essas demandas (Putnam, 1996). A organização ou reestruturação das secretarias estaduais e municipais, gerando melhores serviços para a população ou ampliando o acesso, garantindo a im- plantação ou ampliação de programas de saúde pública, são indicadores significativos de um conjunto mais amplo de mudanças e de experiências inovadoras em curso na gestão local do setor saúde.

Um aspecto metodológico importante vem da constatação da existência de efeitos contraditórios ou perversos, alguns previsíveis, diante da situação de pobreza e de demanda crescente por assistência e atendimento em saúde. Nesse caso, e diante da constatação de que a oferta pública é freqüentemente precária e deficiente, o compromisso com investimentos na rede pública municipal, ultrapassando o circuito clientelista e assistencialista local, já sinaliza mudanças importantes. A ausência ou baixo grau de cultura cívica e participativa entre nós aparece também como outro fator importante que inviabiliza ou dificulta o controle da sociedade sobre as políticas públicas. Assim, a existência e a obrigação da constituição de conselhos municipais de saúde parecem igualmente importantes. Finalmente, diante da baixa capacidade técnica e financeira da grande maioria dos municípios, sua responsabilização crescente quanto à implementação de programas e políticas de saúde traz em si um conjunto considerável de riscos e incertezas.

Essas questões têm sido preocupação constante dos pesquisadores e estudiosos do processo de descentralização das políticas sociais e de saúde (Andrade, 1996; Souza, 1999 e Arretche, 2000). Em tais estudos, algumas variáveis relacionadas às características político-institucionais dos municípios têm sido destacadas: ausência ou fragilidade do corpo técnico burocrático; dependência financeira frente ao governo federal; presença e persistência de arranjos políticos clientelistas; descontinuidade administrativa e dificuldades na contratação e fixação de profissionais mais qualificados nos pequenos municípios ou naqueles mais pobres. São variáveis importantes que explicam indubitavelmente as restrições e limites da descentralização e as profundas variações no desempenho técnicopolítico dos gestores locais na prestação de serviços, fundamentalmente aqueles voltados para educação e saúde.

Em termos metodológicos, a complexidade vem ainda da necessidade de se incluir no quadro analítico tanto variáveis contextuais e explicativas mais gerais do processo político da descentralização, quanto aquelas mais sensíveis ao conjunto de mudanças intrínsecas à administração e à complexidade do setor, tais como indi- 
cadores de mudanças e inovações importantes na organização da assistência, na produtividade dos serviços e na mudança do modelo assistencial. Além disso, no caso da saúde, os princípios do SUS devem ser traduzidos em categorias mais operativas. O desafio é dado pela dificuldade de se definirem variáveis que de fato traduzam avanços no sentido da garantia da universalidade e da integralidade dos serviços, já que indicadores clássicos raramente dão conta de mudanças contextuais mais amplas, no desempenho institucional e no processo na gestão da rede e dos serviços públicos. Assim, uma enorme criatividade é exigida dos pesquisadores mesmo na definição de indicadores aparentemente mais usuais: de investimentos na rede; de resposta dos gestores locais aos incentivos federais ou estaduais; de expansão ou melhoria dos serviços; de aumento dos profissionais contratados; de introdução e consolidação de programas básicos de saúde pública; de desenvolvimento de projetos intersetoriais e de promoção à saúde; de maior envolvimento e participação da comunidade, etc. Em conjunto, podem estar indicando a reorganização da chamada "porta de entrada do sistema de saúde" e, portanto, no médio prazo a melhoria do acesso, a mudança do modelo assistencial vis-à-vis à composição da oferta entre serviços públicos e privados.

Enfim, a argumentação central, e que constitui um dos grandes desafios para os estudos de caráter mais avaliativo, é de que resultados e efeitos virtuosos das transformações em curso, ainda que intermediários - ou seja, mesmo sem dar conta de apontar impactos quer na organização de sistemas locais, isto é, garantindo todos os níveis de complexidade dos serviços de saúde, quer no perfil sanitário da população são imprescindíveis. Mudanças ocorridas no sentido da universalização e da reorganização da rede e das ações básicas em saúde sob responsabilidade municipal podem servir indiretamente para a avaliação do processo de descentralização da rede de serviços de saúde ocorrida no Brasil nos últimos anos da década de 1990. Há que se considerar dentro do contexto de implantação da descentralização que a grande maioria dos municípios, no limiar do novo milênio, não consegue sequer organizar uma rede de atenção básica ou pelo menos encontra grande dificuldade para isso. Assim, qualquer sucesso na implantação ou melhoria dessa rede de serviços parece um passo fundamental para o fortalecimento do SUS no país.

\section{Estratégias de implementação da atenção básica}

Do mesmo modo como na história da condição humana a descoberta equivale à criação e no pensamento sobre a condição humana explicação e compreensão são uma só coisa, assim nos esforços de melhorar a condição humana, diagnóstico e terapia se misturam. (Bauman, 2001)

Um dos instrumentos fundamentais do processo de reforma da saúde foi, sem dúvida, a regulamentação da lei 8.080 de 1990 e da lei 8.142, do mesmo ano, que tratam das normas gerais de funcionamento do SUS, especialmente das transferências intergovernamentais de recursos financeiros para a área. Porém, somente três anos após a lei orgânica é que os critérios para o repasse dos recursos do governo federal para os estados e os municípios tornaram-se efetivos e sistemáticos, através da Norma Operacional Básica do SUS de 1993 (NOB/93).

A NOB/93 entra em vigor no ano seguinte, estabelecendo um processo flexível, gradual e negociado para assegurar viabilidade política à operacionalização da descentralização (Lucchese, 1996). Neste sentido, estabeleceu responsabilidades, requisitos e prerrogativas para a gestão local do SUS, incluindo estados e municípios, sob três modalidades: gestão incipiente, gestão parcial e gestão semiplena. Instituiu ainda novas instâncias colegiadas (as CIB's e CIT's) que se configuravam como arenas de pactuação. Sob a regulamentação da NOB/93, a descentralização, no entanto, caminhou a passos lentos. Até o final de 1997, 57\% dos municípios estavam enquadrados na gestão incipiente ou parcial e apenas $2 \%$ na condição de gestão semiplena. Apesar disso, um dos méritos da NOB/93 foi, sobretudo, o de tornar a descentralização atrativa para estados e municípios, configurando, enfim, uma estrutura legal montada pari passu.

O processo de descentralização se acelera a partir de 1996, quando são implementadas medidas de incentivo, expressas, sobretudo, na Norma Operacional Básica 1996 (NOB/96), para que os municípios assumam a gestão da rede de serviços locais de saúde, numa política deliberada do governo central em prol da municipalização. A NOB/96 também altera as modalidades da gestão local do SUS, que passam a ser apenas duas: plena de atenção básica e plena do sistema de saúde. Em linhas gerais, podemos dizer que a diferença básica entre essas duas modalidades de gestão é o fato de que, na primeira, o poder público municipal tem governabilidade 
apenas sobre a rede de atendimento básico; já na segunda, o município é que gerencia todo o atendimento à saúde no seu território, inclusive a rede hospitalar pública e privada conveniada, tendo para tanto repasse direto de recursos do Ministério da Saúde para o Fundo Municipal de Saúde, sem intermediação da esfera estadual. Uma das questões nevrálgicas do ponto de vista do gestor federal foi especificar mecanismos de regulação de forma a garantir não só algum controle sobre essas transferências, mas torná-las minimamente atrativas. Tendo em vista que o processo vem sendo desde o início negociado nos fóruns especialmente criados dentro do setor e não havendo garantias de receptividade dos estados e municípios, a adesão, que varia de acordo com a diversidade de situações, passava por um cálculo de custos e benefícios políticos, ou seja, entre aquilo que os estados e as municipalidades poderiam ganhar $\mathrm{e}$ perder nesse processo.

A partir de 1998, ano em que a NOB/96 efetivamente entra em vigor, há uma alavancagem importante no ritmo e no alcance do processo descentralizador. De fato, no final do ano de 2000, 99\% dos municípios brasileiros encontravam-se enquadrados em alguma das duas modalidades de gestão definidas pelo Ministério da Saúde, sendo que deste total 89,50\% (4.928 municípios) estavam habilitados na condição Plena de Atenção Básica (Levcovitz et al., 2001).

A principal estratégia do governo ao enfatizar e garantir prioridade ao atendimento básico em saúde se consolida em 1998, com a introdução do PAB (Piso de Atenção Básica), criado através da Portaria GM/MS n.1882, de 18/12/97. $\mathrm{O}$ PAB altera a lógica de repasse de recursos federais para o sistema de prestação de ações médico-sanitárias e se constitui uma medida decisiva na perspectiva da descentralização financeira do sistema de saúde no Brasil, incentivando os municípios a assumirem, progressivamente, a gestão da rede básica de serviços de saúde. Visa garantir aos municípios um valor per capita em torno de $\mathrm{R} \$ 10,00$ repassado pelo governo federal, destinado exclusivamente ao custeio de um elenco predeterminado de procedimentos e ações. A implantação do PAB traz como principal novidade a transferência regular e automática, com repasse federal feito diretamente aos municípios. A condição de habilitação ao PAB é definida pela NOB/96, e obriga a criação do Fundo Municipal de Saúde e do Conselho Municipal de Saúde, dando relativa autonomia e crescente responsabilidade ao gestor munici- pal. Esse novo mecanismo dissocia a produção do faturamento, característica central do sistema anterior. Isto é, através do sistema de pagamento por serviços previamente prestados, os municípios mais pobres e, portanto, sem uma infra-estrutura adequada de unidades e de estabelecimentos de saúde vinham sendo prejudicados. Comparados aos municípios mais desenvolvidos, recebiam do SUS valores menores, porém coerentes, por um lado, com a precariedade da rede de saúde existente no local e, por outro, com a quantidade de procedimentos e atendimentos realizados. Quanto maior o número de hospitais, ambulatórios e postos de saúde maior o valor recebido pelos municípios junto ao SUS. O antigo sistema, através do faturamento com base no número de atendimentos e de procedimentos realizados, perpetuava um modelo de pós-pagamento, incentivando a lógica do aumento crescente de procedimentos e um superfaturamento dos serviços prestados. Procedimentos mais caros usualmente predominavam sobre os mais simples, atuando como um desestímulo à adoção de medidas preventivas e de promoção à saúde. $\mathrm{O}$ PAB introduz uma outra lógica no financiamento da assistência à saúde, dissociando produção e faturamento. Assim, as prefeituras passam a receber regular e diretamente recursos para investir naqueles procedimentos definidos como prioritários e fundamentais para um programa de prevenção e promoção à saúde, consultas médicas e odontológicas, exames de pré-natal, vacinas, vigilância sanitária, etc.

Os recursos do $\mathrm{PAB}$, chegando diretamente aos municípios mais carentes, com maior déficit de atendimentos e com uma rede de serviços de menor complexidade, devem provocar um impacto no médio e longo prazo na oferta de serviços e a introdução de novos programas de saúde pública. Em síntese, o PAB traz algumas inovações importantes na medida que incentiva que uma parcela dos recursos federais, ainda que muito pequena, seja diretamente alocada para o custeio de procedimentos básicos em atenção primária, em uma clara tentativa de organizar a porta de entrada da rede municipal de saúde. O resultado esperado é a capacitação das secretarias municipais para responderem pelo desenvolvimento de programas, ações e procedimentos de atenção básica e de medidas de promoção e prevenção em saúde, ampliando o acesso à saúde. Assim, a expectativa é que o PAB pode alavancar uma lenta e gradual mudança no modelo assistencial, introduzindo me- 
lhorias nas condições de acesso e na qualidade do atendimento prestado na rede pública.

Vale destacar que as mudanças do PAB são introduzidas pari passu aos incentivos ao desenvolvimento de um conjunto de outras medidas: ações de vigilância sanitária e da implantação do Programa de Saúde da Família (PSF) e do Programa de Agentes Comunitários de Saúde (PACS). Para os municípios mais pobres e inteiramente dependentes dos repasses federais, esses incentivos são cruciais, já que eles apresentam capacidade técnica limitada para planejar, organizar e montar uma estrutura de serviços. Os municípios maiores e com maior capacidade técnica reivindicam maior autonomia na aplicação dos recursos, mas são igualmente dependentes dos repasses federais. Outro ponto que parece relevante é que a verba do SUS e de outros convênios da área da saúde, ou seja, a transferência de recursos financeiros do SUS para os municípios, é não só importante, mesmo para os municípios mais ricos e populosos, como atinge quase $2 / 3$ do total de recursos transferidos pela União para a esfera municipal (Prado 17-19/3/2001).

Um poderoso mecanismo de indução utilizado pelo governo federal para priorizar a atenção básica é a adoção do PSF e do PACS. O governo federal lança mão de diversos meios para tornar atraente para os governos locais a adesão a tais programas. O principal incentivo é o financeiro, decisivo para o cálculo político dos gestores municipais em prol da adesão. Ademais, dada a condição de programa estratégico, o Ministério da Saúde vem empenhando esforços no sentido de fornecer suporte técnico e de gestão para a execução das ações previstas.

Inicialmente, o governo federal assumiu como prioridade dentro da agenda setorial a implementação do PACS, existente nos estados nordestinos desde de 1991, visando estender a cobertura do sistema público de saúde às populações rurais e das periferias urbanas, sobretudo para a população materno-infantil. A partir de 1994, num contexto de mobilização dos secretários municipais de saúde em torno da atenção básica, o governo federal assumiu a implantação do PSF como uma estratégia para a mudança do modelo de assistência à saúde no país, prevendo um impacto na reestruturação em todos os níveis de atendimento. As inovações trazidas pelo PACS/PSF parecem residir na vinculação da população a uma equipe básica de saúde, composta por um médico generalista, um enfermeiro, um auxiliar de enfermagem e de quatro a seis agentes comunitários de saúde. É esta equipe que identifica, mediante diagnóstico, as necessidades e organiza a demanda a partir da comunidade, das famílias e dos domicílios, prestando assistência integral e realizando atividades de informação, de orientação e de promoção da saúde.

O desafio aqui é mostrar em que medida os dois programas vêm sendo implementados dentro desse modelo ideal vis-à-vis a um processo rápido de expansão para todo o país. Além disso, cabe indagar se de fato constituem uma estratégia bem-sucedida de promoção à saúde, de mudança do modelo assistencial de base "biomédica", de melhoria do acesso e, enfim, de inclusão social. Isto é, será que o PACS/PSF está de fato mais sintonizado com as políticas de combate à pobreza, de promoção da cidadania e de envolvimento dos setores excluídos?

Parece inquestionável a adequação do programa para o contexto nordestino, dirigido à extensão de cobertura de saúde para populações excluídas, onde $1 / 3$ vive na pobreza absoluta. Já sua viabilidade e adaptação ao contexto de grandes áreas de periferia urbana, no sudeste brasileiro, onde a concentração espacial da população significa concentração das carências, provocam novas questões. Nesses locais as soluções passam quase sempre pela reorganização da rede de saúde e de seu corpo técnico e não pela montagem de estruturas de atendimento paralelas. Uma das razões parece residir exatamente no custeio do programa, no caso do PSF, que deve ser assumido, em parte, pelas prefeituras.

A implementação e gestão da rede de atendimento básico, se bem que coordenada e induzida centralmente, foi delegada de fato aos municípios, provocando não só inovações, mas alguns efeitos perversos nos demais níveis do sistema (Oliveira, 1995), como é o caso daqueles municípios que possuem uma rede de serviços mais complexa. Nesses municípios, a dificuldade é reestruturar os investimentos locais em saúde para uma progressiva e necessária mudança do modelo assistencial. Os municípios situados nas regiões e estados mais desenvolvidos tendem a reunir os requisitos básicos necessários para assumirem a gestão descentralizada e o desenvolvimento de ações mais complexas, visando à integralidade do atendimento, à otimização dos resultados e à eficiência na utilização de recursos, já que, teoricamente, dispõem de maior capacidade técnica e gerencial, bem como maior aporte de recursos financeiros. 
Cabe considerar que a oposição às vezes explícita outras vezes sutil à política e ao modelo de fortalecimento e de priorização da atenção básica acaba por desqualificar outras questões fundamentais: a inadequação do modelo de saúde vigente e o fenômeno da desigualdade social, implicando a existência de um contingente considerável de população com dificuldade de acessar e se beneficiar das ações e serviços de saúde. O que deve ser enfatizada, por outro lado, é a necessidade de adequação dessa política aos contextos e realidades locais. Há considerável evidência empírica a respeito da acentuada diferença em relação ao fenômeno da pobreza rural, notadamente no Nordeste, e da pobreza concentrada, visível e escancarada presente nas periferias e favelas das áreas metropolitanas. Isso certamente tem que ser considerado, justificando a adoção de perfis ou modelos assistenciais diversos e mais adequados.

Diante da constatação de que os recursos públicos são escassos e finitos, é crucial determinar onde investir e o que universalizar e disponibilizar como atividade, programa e serviço, tamanhos são os descompassos e vicissitudes entre os princípios do SUS e sua execução como política pública em um país, é necessário insistir, com enormes desigualdades sociais e regionais, onde a pobreza, a miséria extrema e a exclusão social devem ser enfrentadas com políticas públicas adequadas. A discussão sobre o processo de accountability dos gestores e da eficiência e responsabilidade na utilização dos recursos públicos ganha importância crescente, assim como o desempenho político-institucional das prefeituras e a capacidade de gestão local.

A pergunta-chave aqui é em que medida a política de reorganização da atenção básica e a pequena mudança na alocação de recursos advinda da implementação da descentralização no setor tem sido suficiente para modificar o padrão de desigualdade no acesso aos bens e serviços de saúde, dado pela própria heterogeneidade e desigualdade social existente no país. Questões determinantes como o aumento dos custos e o declínio da qualidade dos serviços, características gerais (e globais) do setor saúde, remetem diretamente a centralidade da discussão para a prioridade nos investimentos em programas de promoção e de atenção básica, tendo em vista a necessidade de universalização da atenção primária em saúde. No caso do Brasil, devemos ficar atentos a nossa realidade: enormes desigualdades sociais, intenso processo de urbanização a partir das últimas décadas e a limitação de recursos, onde necessidades e demandas crescem e se tornam bastante complexas rapidamente, tendendo ao que parece ultrapassar a capacidade de resposta das políticas públicas e dos sistemas de saúde.

\section{Municípios e descentralização dos serviços de saúde}

... A descentralização é a condição para a eficácia política em razão da exigência de fluxo de informação a partir da base e do reconhecimento de sua autonomia (Giddens, 2001). Mesmo não havendo automatismo entre descentralização e maior accountability e controle social, como chama a atenção Giddens, o processo de descentralização, com todos os problemas e críticas, parece constituir-se em um avanço no caminho do diálogo entre as políticas públicas e a sociedade. Trata-se de acentuar a importância na sociedade moderna de reinventar e ampliar espaços de diálogo político, de negociação e de consenso a partir dos interesses e contextos locais. A descentralização, em situação de permanente déficit de democracia e de responsabilidade com a gestão pública, embora sob risco de ser encapsulada no circuito do clientelismo/assistencialismo de viés populista, constitui pré-requisito para o fortalecimento da cidadania e do controle social.

No caso da política de saúde e de implantação do SUS, um aspecto crucial, sem dúvida, foi a criação dos Conselhos de Saúde nas diversas instâncias de gestão do sistema, indicando uma nova institucionalidade e a ampliação do espaço e da agenda pública. Os Conselhos Municipais de Saúde (CMS), na medida em que constituem pré-requisito para a habilitação dos municípios na gestão descentralizada, estão presentes, hoje, como se sabe, na esmagadora maioria dos municípios brasileiros. Se esse processo tem levado a um melhor desempenho setorial e maior accountability dos gestores públicos é algo que vem sendo avaliado e merece maior aprofundamento. A baixa capacidade de controle social exercido a partir dos Conselhos Municipais tem sido apontada por diversos estudos, mesmo em locais com tradição na organização de associações de moradores e de movimentos sociais em geral, como no caso do município de Duque de Caxias, no Rio de Janeiro (Bodstein et al., 1999). Certamente, de antemão, já sabemos dos diversos problemas com a capacitação dos conselheiros e de todos os riscos de serem manipulados politicamente pelo poder local.

Convém chamar a atenção para a tese da futilidade, tão brilhantemente desenvolvida por Hirschman (1992). Baseia-se no argumento de que o diagnóstico de um programa social - a crítica ao seu funcionamento e aos resultados 
negativos ou pouco expressivos - não invalide e não anule a proposta original e seus princípios gerais. Como nos mostra o autor, a tensão entre as metas anunciadas de um programa social e sua real efetividade é algo bem mais complexo. (Hirschman, 1992). Assim, ao que parece, a proposta dos CMS está sintonizada com a necessidade de maior e melhor interlocução entre o poder público e a sociedade, visando responder de forma mais eficiente e com maior equidade às demandas sociais. $\mathrm{O}$ processo de descentralização vis-à-vis à existência dos conselhos parece estratégia crucial de fortalecimento do espaço público.

Ainda que fundamentais para o fortalecimento do capital social local, os conselhos dependem em grande parte do desempenho do poder público, como nos lembra Putnam (1996). Isto é, quanto melhor a capacidade de gestão pública local, melhor o funcionamento dos conselhos; sendo assim, a virtude cívica floresce e se desenvolve mais facilmente onde os meios institucionais são mais propícios. Desse ponto de vista, quanto maior a capacidade de gestão, de planejamento das atividades e prioridades, o monitoramento e a avaliação de seus resultados, tanto maior o espaço para a participação e o controle social. Tal questão coloca na agenda setorial a necessidade de capacitação e formação de gestores e de conselheiros, assim como a divulgação de programas bem-sucedidos, as chamadas best practices, importantes como efeito demonstração. No caso da maioria dos municípios, formação e capacitação técnica são processos fundamentais para o melhor desempenho das políticas de cunho social.

Outro aspecto que decorre dessa perspectiva de análise vem da constatação de que apesar do papel fundamental e insubstituível do poder público é cada vez mais presente e mais importante a colaboração e a formação de parcerias com os demais setores organizados da sociedade. Junte-se a isso a centralidade que adquire para a gestão municipal e para a solução dos problemas sociais o desenvolvimento de políticas intersetoriais: saneamento, habitação, educação, geração de trabalho e renda, etc.

O ritmo acelerado da descentralização municipal no setor saúde vem demonstrando a existência de inúmeras modalidades de organização dos sistemas locais, originadas da combinação entre normas institucionais do SUS, as singularidades socioeconômicas e as determinações do jogo político local. Demonstram a criatividade dos gestores locais diante dos enor- mes desafios. As experiências são desiguais e de difícil avaliação. O diálogo entre academia e gestores adquire crescente importância. No caso da pesquisa e dos estudos de caráter acadêmico, é crucial, mais do que nunca, a capacidade de identificar as perguntas pertinentes e buscar o desenho de investigação mais adequado, assim como a geração de informação que traga subsídios para os gestores e a sociedade de uma maneira geral. $\mathrm{O}$ fato é que experiências virtuosas no setor saúde apontam para a melhoria no desempenho gerencial e na maior responsabilidade social como principais determinantes do fortalecimento do SUS nos municípios. A reorganização da rede de serviços locais de saúde, tanto em termos quantitativos como qualitativos, representa um processo fundamental na reforma setorial e fortemente dependente da capacidade de gestão. Como ressaltamos anteriormente, as variações no desempenho gerencial explicam, em grande parte, as variações em termos de resultados e impactos na saúde da população.

\section{O papel indutor do nível central}

Importa considerar se, de fato, a política do governo federal nas últimas décadas vem induzindo a organização e fortalecimento técnico-gerencial das secretarias municipais. Parece evidente que na medida em que uma série de prérequisitos para a habilitação dos municípios (plano de saúde municipal, conta PAB, relatório de gestão, fundo de saúde, implantação dos bancos de dados nacionais de saúde, a criação dos CMS) é exigida, essa é uma preocupação presente na estrutura normativa montada. Importa também reconhecer que é exatamente esse conjunto integrado de medidas, e não uma medida isoladamente, que constitui o traço inovador no desenho da reforma sanitária brasileira e no processo de descentralização em saúde.

Por outro lado, as análises do processo de implementação da descentralização da saúde têm evidenciado o despreparo da esfera municipal e a precariedade da sua estrutura técnicoadministrativa voltada à prestação de serviços de saúde, não sendo raros os exemplos em que a própria montagem dessa estrutura coincide com o momento em que o município assume a gestão da rede de serviços e passa a receber diretamente os recursos federais. Assim, a municipalização dos gastos em saúde, consolidada nos últimos anos da década passada, tem como 
contrapartida um esforço crescente e uma enorme responsabilidade do município na gestão da rede de serviços de saúde e na melhoria das condições de saúde.

Nesse cenário, tem sido fundamental o papel da esfera estadual no ritmo e no alcance das mudanças em curso, já que estratégias de microrregionalização e outras inovações gerenciais têm sido incentivadas. Ainda que limitadas dentro do conjunto dos municípios brasileiros, as iniciativas como as atuais experiências em formação de Consórcios Intermunicipais e outras formas de colaboração expressam arranjos e parcerias fundamentais para a ampliação e diversificação dos serviços. De fato, sem a efetiva coordenação e planejamento regionais, correse o risco de que o processo de descentralização se pulverize e perca efetividade, distanciando-se dos principais objetivos do SUS.

Apesar das profundas mudanças, o contexto da descentralização no país é marcado, na grande maioria dos municípios, por uma precariedade e fragilidade estrutural tanto de instalações e capacidade física quanto de recursos humanos e técnicos. Assim, o desafio na implementação da reforma setorial passa pela organização e produção de uma enorme gama de serviços e ações de saúde voltados para uma clientela potencial de 170 milhões de pessoas, com 75\% deste total quase inteiramente dependente do setor público.

A eficiência na gestão pública, e a capacidade de regulação crescente do estado e de controle social são cruciais, mas não suficientes. $\mathrm{O}$ bom desempenho do setor depende de capacidade técnica adequada. A escassez de recursos financeiros e técnicos e a falta de investimentos constituem a realidade do setor, agravada pela distorção e desequilíbrio na alocação de recursos. Porém, tal realidade freqüentemente serve para esconder a falta de eficiência e de compromisso com as demandas sociais.

Por outro lado é necessário reconhecer que não há automatismo entre inovações gerenciais e melhor desempenho administrativo que garanta melhores resultados. Existem, por exemplo, vários municípios enquadrados na GPSM que não conseguem sequer implementar serviços básicos de saúde pública, como no caso de municípios da região norte do país. Do mesmo modo, municípios mais ricos não estão mais bem capacitados e nem mais comprometidos com a demanda e com a organização da oferta de saúde. Indicadores de expansão da rede física nos dizem muito pouco sobre a composição da oferta entre o setor público e o privado na prestação de serviços de saúde, sobre a natureza do modelo ou do perfil assistencial e sobre a presença e equilíbrio entre os diversos níveis de atendimento: básico e ambulatorial por um lado e de média e alta complexidade, por outro.

\section{Conclusões}

O argumento central do artigo foi no sentido de mostrar a importância que o fortalecimento e a reorganização da atenção básica adquirem no contexto da política setorial nos últimos anos. O ponto nevrálgico do debate talvez seja a compreensão, e um possível consenso, em relação à necessidade, ainda hoje, de universalização de um conjunto de ações e serviços básicos e de atenção primária em saúde pública de base municipal. De fato, uma das principais conclusões deste artigo é de que as inovações e os resultados alcançados têm de ser avaliados dentro do contexto de mudanças mais gerais que decorrem do papel indutor do nível central e da capacidade de resposta e de adequação dos municípios na gestão e prestação de serviços e atividades relacionadas a este nível de atenção.

A estruturação da rede de atendimento básico vem sendo um enorme desafio para a maioria dos municípios do país ainda hoje. Dessa forma, a tarefa de coordenar em nível local o incremento da atenção básica com as demandas por média e alta complexidade e os princípios da integralidade do atendimento parece ainda mais complexa, mostrando a importância das diversas propostas em curso de regionalização e de criação de consórcios intermunicipais. A integralidade da atenção como princípio do SUS é inquestionável. Mas, sem o fortalecimento da rede básica de serviços e mudança do modelo assistencial, sua implementação e resultados são extremamente incertos.

A responsabilidade municipal com a organização da atenção básica e com a prestação de serviços a partir da introdução do $\mathrm{PAB}$ em 1998, isto é, da implantação de um sistema de pré-pagamento, de fato, vem se constituindo em um poderoso instrumento de mudança e, indiretamente, de capacitação dos gestores locais, devendo trazer, no médio prazo, impactos positivos na oferta e na qualidade dos serviços. Nesta perspectiva, é imprescindível a conjugação de esforços e um certo consenso entre os três níveis da administração pública e a persistência desses arranjos ao longo do tempo, ga- 
rantindo uma saudável autonomia técnico-administrativa diante das constantes mudanças no jogo político-eleitoral.

A ausência de recursos humanos em saúde, com capacitação técnica adequada, com salários e condições de trabalho atrativos vis-à-vis à falta de equipamentos médicos, mesmo os mais simples, constitui ainda hoje uma realidade para a esmagadora maioria dos municípios brasileiros e grande obstáculo ao bom desempenho da gestão municipal.

Metodologicamente foi ressaltada a importância em se distinguir, sem necessariamente separar, princípios e concepções programáticas do processo institucional de implementação. Por outro lado, foi mostrada a necessidade de se priorizar a avaliação de processo vis-à-vis a contextos específicos. Daí que é fundamental avaliar as inovações no âmbito gerencial e no desempenho institucional para uma posterior avaliação de resultados e impactos mais substanciais. Dada a reconhecida fragilidade institucional das secretarias de saúde nos municípios, assim como da própria rede local de serviços, políticas e programas de fortalecimento e de reorganização da atenção básica continuam a ser prioritários, assim como a avaliação do desempenho institucional.

Como porta de entrada do sistema e de ampliação da cobertura e do acesso, minorando o déficit na oferta de serviços de saúde, são necessários investimentos na construção, ampliação e manutenção da rede de atenção básica. O risco continua sendo a inauguração apressada de módulos de saúde, (principalmente postos e/ou minipostos periféricos), sem nenhuma capacidade efetiva de atendimento. Instalados em virtude de seu forte apelo eleitoral, esses módulos vão, de certa forma, ao encontro das demandas da população. Porém, sem referência a uma proposta mais consistente e um conjunto mais amplo de medidas e mudança na reorganização no modelo assistencial vis-à-vis à introdução de novos programas de saúde coletiva, como nos referimos anteriormente, esse investimento parece infrutífero. A mudança do modelo assistencial é fundamental ainda para diminuir a dependência do setor público diante do setor privado, interessado diretamente na crescente medicalização e hospitalização dos procedimentos na área de saúde. Enfim, em termos metodológicos, a avaliação da atenção básica tem de ser concebida a partir da sua implementação no âmbito municipal com base em um conjunto coerente e integrado de medidas e programas.

Fortemente induzida pelo governo central e com pequena (porém crescente) interferência do nível estadual, o processo de reorganização da atenção básica é indissociável das inovações e mudanças no desempenho da gestão local e da relativa autonomia dos municípios em termos de implementação de atividades e programas de saúde pública. A proposta de universalização da atenção básica, atualmente em curso, não pode ser avaliada de forma isolada, sem o contexto mais geral da política setorial e do conjunto de medidas e programas implantados a partir de 1998 e que, de fato, dão sentido à proposta: o PAB fixo, o PACS/PSF e os demais incentivos que compõem a parte variável do PAB. Deve ser vista como uma estratégia legítima e efetiva de descentralização da promoção e da assistência médico-sanitária e de ampliação do direito à saúde ainda não inteiramente garantido pelo poder público. Como programa de saúde coletiva e acompanhado por políticas intersetoriais, exerce um papel central junto às políticas de combate à pobreza e à exclusão social. Além disso, os custos crescentes das ações médicas e terapêuticas, bem como o declínio da qualidade do atendimento tornam as estratégias de reorganização e fortalecimento das ações básicas e de desenvolvimento da atenção primária um mecanismo efetivo de ampliação da oferta de saúde e de extensão de cobertura, especialmente em áreas carentes de outros recursos médico-assistenciais. São questões aparentemente óbvias, mas que, ainda hoje, parecem extremamente úteis para o avanço do debate $\mathrm{e}$ da discussão sobre os rumos do SUS entre nós. 


\section{Referências bibliográficas}

Andrade I 1996. Descentralização e poder municipal no Nordeste: os dois lados da nova moeda. Trabalho apresentado ao GT de Políticas Públicas do XX Encontro Nacional da ANPOCS. Caxambu.

Arretche M 2000. Estado federativo e politicas sociais: determinantes da descentralização. FAPESP-Editora Revan, São Paulo.

Bauman Z 2001. Modernidade líquida. Jorge Zahar Editor, Rio de Janeiro.

Bodstein R, Senna M \& Souza R 1999. Novos desafios à gestão em saúde: a experiência do município de Duque de Caxias/RJ. Revista de Administração Pública. (RAP) 33(4):63-79, jul./ago.

Denis JL \& Champagne F 2000. Análise da implantação, pp. 49-88. In Hartz Z (org.). Avaliação em saúde: dos modelos conceituais à prática na análise da implantação de programas. Fiocruz, Rio de Janeiro

Geertz C 2001. Nova luz sobre a antropologia. Jorge Zahar editor, Rio de Janeiro.

Giddens A 2001. Em defesa da sociologia (ensaios, interpretações e tréplicas). Unesp, São Paulo.

Hartz Z \& Camacho LAB 1996. Epidemiologia e avaliação de serviços de Saúde. Cadernos de Saúde Pública 12(2).

Hartz Z 1999. Avaliação dos programas de saúde: perspectivas teórico-metodológicas e políticas institucionais. Ciência \& Saúde Coletiva 4(2):341-354.

Hartz Z 2000 (org.). Avaliação em saúde: dos modelos conceituais à prática na análise da implantação de programas. (1a reimpressão). Fiocruz, Rio de Janeiro.
Hirschman A 1992. A retórica da intransigência (perversidade, futilidade, ameaça). Companhia das Letras, São Paulo.

Levcovitz E, Lima LD \& Machado CV 2001. Políticas de saúde nos anos 90: relações intergovernamentais e o papel das Normas Operacionais Básicas. Ciência \& Saúde Coletiva 6(2):269-291.

Lucchese P 1996. Descentralização do financiamento e gestão da assistência à saúde no Brasil: a implementação do sistema único de saúde - retrospectiva 1990/ 1995. Rio de Janeiro, Planejamento e Políticas Públicas IPEA, 14:76-156.

McKinlay JB 1996. More appropiate evaluation methods for comumunity - level interventions. Evaluation Review 20(3):237-243.

Mohr RLB 1992. Impact analysis for program evaluation. Sage Publications, Beverly Hills.

Oliveira A F 1995. Os dilemas da municipalização no contexto de uma região metropolitana: o caso de Campinas. XX Encontro Anual da Associação Nacional de Pós-Graduação em Ciências Sociais (ANPOCS). Caxambu.

Prado MCRM 2001. Jornal Gazeta Mercantil. Edição de 16, 17 e 18 de março. São Paulo pp. A-3.

Putnam R 1996. Comunidade e democracia. (A experiência da Itália moderna). FGV, Rio de Janeiro.

Souza C 1999. Redemocratização, federalismo e gasto social no Brasil: tendências recentes. XXIV Encontro anual da Associação Nacional de Pós-Graduação em Ciências Sociais (ANPOCS). Petrópolis. 